\title{
Сорбция коричной и гидроксикоричных (кофейной и хлорогеновой) кислот, таксифолина и умбеллиферона на активном угле БАУ-А
}

\author{
(C) 2020 Подолина Е.А. ${ }^{1,2,3}$, Ханина М.А. ${ }^{2}$, Мухин В.М. ${ }^{3}$, Лежнина М.Г. ${ }^{2}$, \\ Кузнецова Ю.А. ${ }^{2}$, Небольсин А.Е. ${ }^{4}$ \\ ${ }^{I}$ ФББОУ ВО Московский политехнический университет (филиал в г. Электросталь), Электросталь \\ ${ }^{2}$ ОГОУ ВО Государственный гуманитарно-технологический университет, Орехово-Зуево \\ ${ }^{3}$ АО ЭНПО «Неорганика», Электросталь \\ ${ }^{4} \mathrm{OAO}$ «Партнер», Воронеж
}

Поступила в редакцию 14.01.2020 г.

DOI: $10.17308 /$ sorpchrom.2020.20/2778

К мономерным полифункциональным природным биологически активным вешествам (БАВ) растительного происхождения относят коричную и гидроксикоричные (кофейная, хлорогеновая) кислоты, кумарины (умбеллиферон) и таксифолин, которые в небольших количествах содержатся практически во всех лекарственных растениях (ЛРС). Целью настоящего исследования является изучение адсорбционной и десорбционной способности БАВ на активном угле БАУ-А.

Адсорбцию БАВ осуществляли из растворов стандартных образцов на активном угле БАУ-А с размером частиц 2.8-2.0 мм. Адсорбцию БАВ осуществляли в стационарных условиях при ламинарном перемешивании (на смесителе Shaker 3.02) и при турбулентном перемешивании (смесителе типа Vortex). Экспериментально определены времена достижения сорбционного равновесия БАВ и их степени сорбции. Так при ламинарном перемешивании наиболее полное сорбирование происходит в течение 15-30 мин, а при турбулентном - за 3-6 мин. Полученные изотермы сорбции БАВ на БАУ-А принадлежат к L-типу (коричная кислота и умбеллиферон) и S-типу (КфК, ХгК, ТФ) согласно классификации Гиббса и подтверждают физический механизм сорбции.

По изотермам адсорбции рассчитаны физико-химические параметры с использованием теории мономолекулярной адсорбции (уравнения Фрейдлинха, Ленгмюра), полимолекулярной адсорбции (модель БЭТ) и теории объемного заполнения микропор (уравнение Дубинина-Радушкевича). Полученные величины энергии Гиббса подтверждают, что природные фенольные соединения адсорбируются в микропорах за счет ван-дер-ваальсовых сил, а поверхностные функциональные группы АУ образуют водородные связи сорбат-сорбент.

Десорбцию БАВ осуществляли в динамических условиях на колонке длиной 180 мм, диаметром 15 мм, высота слоя АУ 20 мм. В качестве элюирующих растворов применены полярные индивидуальные (метанол) и бинарные (вода - этанол $\left(\varphi_{2}=0.5\right)$, вода - ацетонитрил $\left(\varphi_{2}=0.8\right)$ растворители. Все элюирующие растворители в течение 30 мин элюируют БАВ на $73-83 \%$.

Таким образом, получено, что АУ БАУ-А является эффективным адсорбентом по отношению к коричной и гидроксикоричным кислотам, умбеллиферону и таксифолину. Для элюирования БАВ можно применять метанол или бинарные смеси (вода - этанол или вода - ацетонитрил) при этом из сорбента БАУ-А можно выделить практически 83\% БАВ. Активный угол БАУ-А (ГОСТ 6217-74 ОА ЭНПО «Неорганика» г. Электросталь, Московской области) рекомендован для выделения коричной и гидроксикоричных кислот, умбеллиферона и таксифолина из водных растворов.

Ключевые слова: активный уголь, адсорбция, десорбция, коричная и гидроксикоричные (кофейная и хлорогеновая) кислоты, таксифолин, умбеллиферон, 


\section{Введение}

Мономерные полифункциональные природные биологически активные вещества (БАВ) растительного происхождения такие как коричная, гидроксикоричные (кофейная и хлорогеновая) кислоты, таксифолин и умбеллферон часто применяют в пищевой (стабилизаторы жиров и красителей), косметической (стабилизация компонентов кремов) и фармацевтической (приготовление различных лекарственных препаратов) промышленности [1-6]. Предварительно такие БАВ извлекают из растительного сырья различными методами твердожидкостной экстракции (ТЖЭ )[7-11], а затем выделяют с помощью сорбентов [12-16].

Различные марки активных углей (АУ), например, БАУ являются эффективными сорбентами для концентрирования и последующего выделения БАВ, например, рутин и танин [17-19]. В тоже время сорбция коричной кофейной и хлорогеновой кислоты, таксифолина и умбеллиферона активными углями практически не изучалась.

\section{Теоретическая часть}

Современные исследования, проводимые в микрообъемах (in vitro) [20, 21], позволяют значительно снизить расходы химических реактивов, а интенсивное (турбулентное) перемешивание в системе сорбент-контактный раствор значительно снижает время проведения эксперимента. В настоящей работе изучена сорбция коричной и гидроксикоричных (кофейной, хлорогеновой) кислот, таксифолина и умбеллиферона на активном угле БАУ-А в различных режимах перемешивания (ламинарное и турбулентное) при соотношении массы сорбента и объема контактного раствора (0.025:5).

Целью настоящего исследования является изучение процессов сорбции и десорбции БАВ на примере коричной и гидроксикоричных (кофейная и хлорогеновая) кислот, таксифолина и умбеллиферона на активном угле БАУ-А.

\section{Эксперимент}

Реактивы: этанол, раствор для наружного применения и приготовления лекарственных форм с концентрацией 95 об. \% (ПХФК ОАО «Медхимпром»); ацетонитрил, квалификация (хром. ч), метанол, квалификации х.ч. (массовая доля 99.5\%); водноэтанольные растворы (объемная доля этанола 50\%) стандартных образцов (ГСО) коричной (КрК), кофейной (КфК), хлорогеновой (ХГК) кислот, таксифолина (ТФ) и умбеллиферона (УМ); состав элюирующих растворов: вода - этанол (объемная доля этанола 50\%); вода - ацетонитрил (объемная доля ацетонитрила 80\%), метанол. Сорбент БАУ-А (ГОСТ 6217-74) изготовлен в НПО «Неорганика», г. Электросталь Московской области.

Оборудование: количественное определение БАВ в растворах осуществляли методом УФ-спектрофотометрии (спектрофотометр UNICO, модель 2800), аналитические длины волн (АДВ) БАВ (табл.1, рис. 1); перемешивание раствора и сорбента осуществляли на вибросмесителе (Shaker 3.02), с частотой вращения v=150 об/мин (ламинарное перемешивание) и на смесителе типа Vortex, скорость перемешивания 15000 об/мин (турбулентное перемешивание).

Методика выполнения эксперимента: исследования сорбции БАВ на БАУ-А осуществляли в статических условиях из растворов ГСО при температуре $22 \pm 2^{\circ} \mathrm{C}$ (293-297 К), при постоянном перемешивании, $\mathrm{pH}=7$. Навеску АУ БАУ-А ( 0.025 г, взвешенную с погрешностью \pm 0.2 мг) помещали в коническую колбу вместимостью $50 \mathrm{~cm}^{3}$ с притертой крышкой, добавляли $5 \mathrm{~cm}^{3}$ водно-этанольного раствора БАВ с концентрацией 100 мкг/см³ , помещали на вибросмеситель (Shaker 3.02), перемешивали в 
ламинарном режиме, через каждые 5 мин отбирали пробу контактного раствора и определяли концентрацию БАВ спектрофотометрическим методом.

Таблица1. Структурные формулы и некоторые физико-химические свойства БАВ

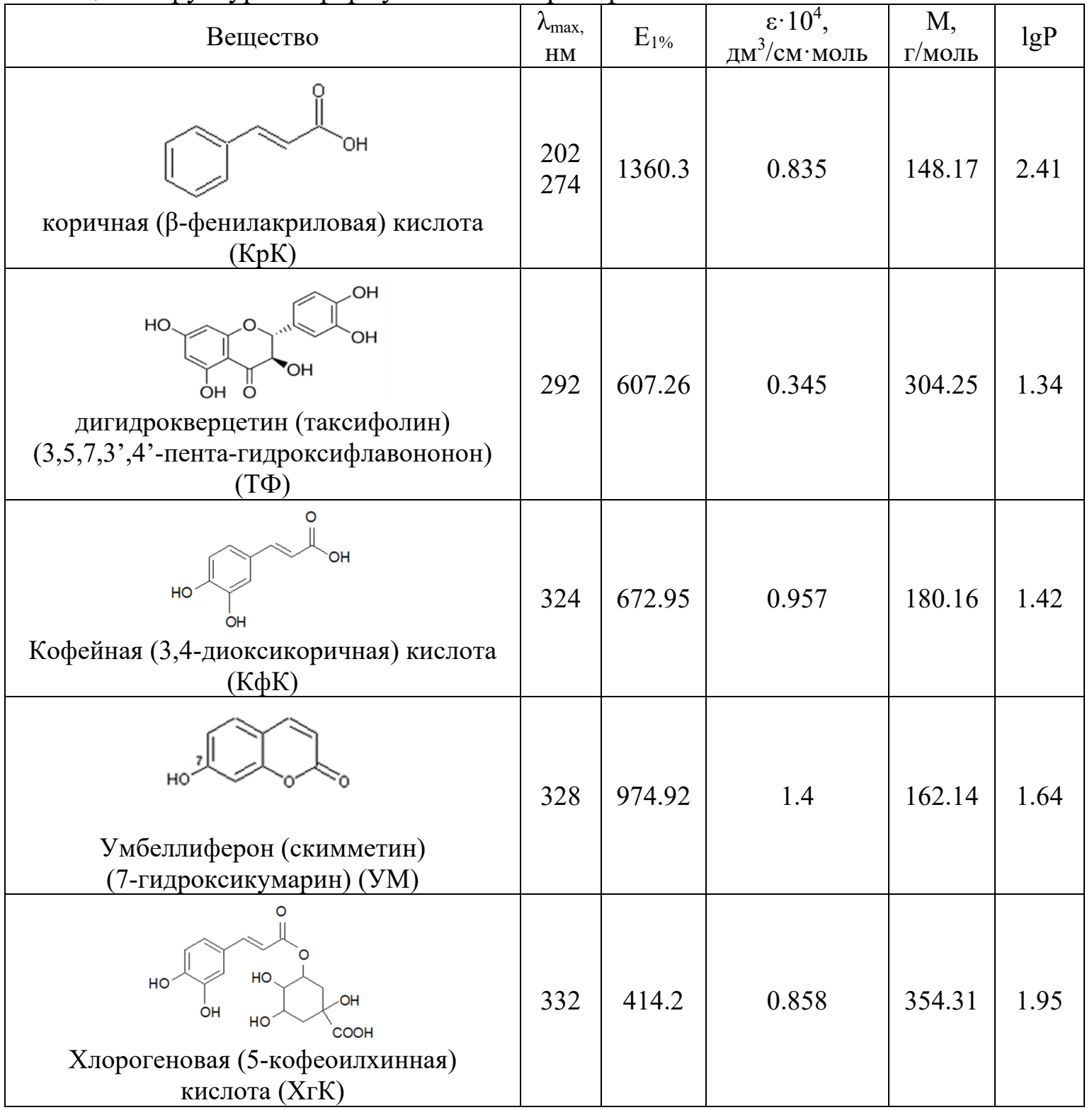

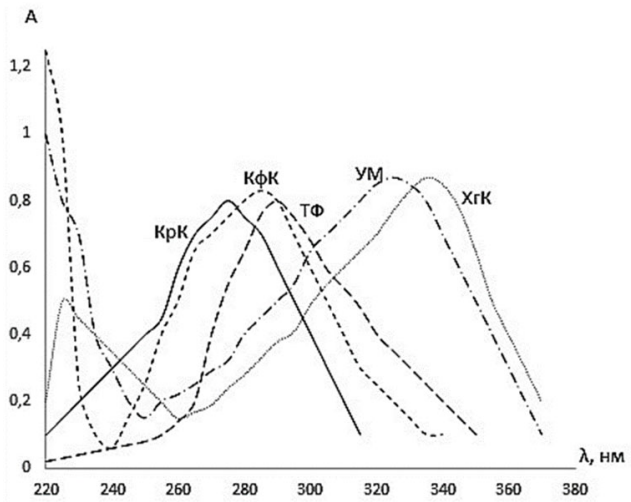

Рис. 1. УФ-спектры водно-этанольных растворов БАВ:

КрК - коричная кислота; КфК - кофейная кислота; ТФ - таксифолин;

УМ - умбеллиферон; ХгК - хлорогеновая кислота. 
Сорбцию БАВ при турбулентного перемешивания осуществляли по следующей методике: навеску АУ БАУ-А ( 0.025 г, взвешенную с погрешностью \pm 0.2 мг) помещали в центрифужную пробирку вместимостью $50 \mathrm{~cm}^{3}$, добавляли $5 \mathrm{~cm}^{3}$ водноэтанольного раствора БАВ с концентрацией 100 мкг/ $\mathrm{cm}^{3}$, помещали на платформу смесителя Vortex, перемешивали в турбулентном режиме, через каждую минуту в течение 6 минут отбирали пробу контактного раствора и определяли концентрацию БАВ спектрофотометрическим методом.

Десорбцию БАВ из сорбента осуществляли в динамических условиях: в колонку длиной 180 мм, диаметром 15 мм помещали АУ (высота слоя 20 мм), в качестве элюента применялись бинарная смесь вода - этанол (объемная доля этанола 50\%); вода - ацетонитрил (объемная доля ацетонитрила 80\%) [22]; метанол (99.5 масс. \%).

Концентрацию БАВ в растворах рассчитывали по уравнению градуировочной прямой: $A=\mathrm{k}_{\text {дд }} \cdot \mathcal{C}$, где $\mathrm{A}$ - оптическая плотность исследуемого раствора, с - концентрация БАВ, мкг $/ \mathrm{cm}^{3} ; \mathrm{k}_{\text {уд }}$ удельный показатель поглощения БАВ, $\mathrm{cm}^{3} / \mathrm{M \kappa г} \cdot \mathrm{cm}$.

Расчет величины адсорбции и десорбции, а также обработку полученных изотерм и физико-химических параметров сорбции БАВ проводили с учетом компьютерных программ «Statisticafor Windows 7.0».

\section{Обсуждение результатов}

В табл. 2 приведены экспериментально определенные времена достижения сорбционного равновесия БАВ, степени их сорбции (R, \%). Полученные результаты статистически обработаны, относительная погрешность определения $(\delta c)$ при доверительной вероятности (Р) не превышает 10\%.

Таблица 2. Время достижения ( $\mathrm{t}$, мин) сорбционного равновесия, и величина степени сорбции $\mathrm{R}, \%$ ГСО растворов БАВ на АУ БАУ-А; размер частиц АУ - 2.8-2.0 мм; $\mathrm{n}=5$; $\mathrm{P}=0.95 ; \mathrm{S}^{2}=0.0019 \div 0.010 ; \mathrm{S}=0.04 \div 0.11 ; \mathrm{S}_{\mathrm{r}}=0.07 \div 0.11 ; \delta \mathrm{c}=4 \div 9 \%$

\begin{tabular}{|c|c|c|c|c|c|c|c|c|c|c|c|c|}
\hline \multirow{2}{*}{ БАВ } & $\mathrm{t}$ & $\mathrm{R}, \%$ & $\mathrm{t}$ & $\mathrm{R}, \%$ & $\mathrm{t}$ & $\mathrm{R}, \%$ & $\mathrm{t}$ & $\mathrm{R}, \%$ & $\mathrm{t}$ & $\mathrm{R}, \%$ & $\mathrm{t}$ & $\mathrm{R}, \%$ \\
\hline & \multicolumn{12}{|c|}{ Ламинарное перемешивание } \\
\hline \multirow{2}{*}{ КрК } & \multirow{10}{*}{$\begin{array}{l}\sum_{n}^{I} \\
n\end{array}$} & 89.4 & \multirow{10}{*}{$\begin{array}{l}\bar{I} \\
\vdots \\
0\end{array}$} & 89.9 & \multirow{10}{*}{$\begin{array}{l}\bar{E} \\
\sum_{n} \\
\Omega\end{array}$} & 93.5 & \multirow{10}{*}{ 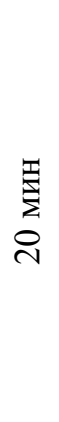 } & 95.1 & \multirow{10}{*}{$\begin{array}{l} \pm \\
\sum \\
\Sigma \\
i\end{array}$} & 96.1 & \multirow{10}{*}{$\begin{array}{l}\frac{I}{\sum_{n}} \\
\text { o } \\
\text { m }\end{array}$} & 98.3 \\
\hline & & \pm 1.1 & & \pm 1.1 & & \pm 1.5 & & \pm 1.4 & & \pm 1.7 & & \pm 1.4 \\
\hline ТФ & & 90.3 & & 91.6 & & 94.5 & & 96.2 & & 97.3 & & 99.1 \\
\hline $1 \Psi$ & & \pm 1.6 & & \pm 1.5 & & \pm 1.3 & & \pm 1.7 & & \pm 1.8 & & \pm 1.6 \\
\hline КфК & & 89.1 & & 90.4 & & 92.4 & & 94.8 & & 96.3 & & 98.5 \\
\hline К中і & & \pm 1.3 & & \pm 1.2 & & \pm 1.2 & & \pm 1.6 & & \pm 1.9 & & \pm 1.8 \\
\hline УМ & & 89.1 & & 90.3 & & 93.1 & & 95.3 & & 97.1 & & 98.7 \\
\hline & & \pm 1.1 & & \pm 1.6 & & \pm 1.5 & & \pm 1.7 & & \pm 1.7 & & \pm 1.4 \\
\hline \multirow{3}{*}{ ХгК } & & 90.2 & & 92.5 & & 94.3 & & 96.1 & & 97.9 & & 99.1 \\
\hline & & \pm 1.5 & & \pm 1.7 & & \pm 1.3 & & \pm 1.8 & & \pm 1.8 & & \pm 1.7 \\
\hline & \multicolumn{12}{|c|}{ Турбулентное перемешивание } \\
\hline \multirow{2}{*}{ КрК } & \multirow{10}{*}{$\underset{-}{\sum_{-}}$} & 85.6 & \multirow{10}{*}{$\begin{array}{l}\sum_{\Delta}^{ \pm} \\
N\end{array}$} & 87.9 & \multirow{10}{*}{ 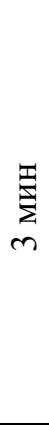 } & 92.4 & \multirow{10}{*}{$\begin{array}{l}\sum_{\Delta}^{E} \\
\sigma\end{array}$} & 94.6 & \multirow{10}{*}{$\begin{array}{l}\sum_{n} \\
n\end{array}$} & 96.3 & \multirow{10}{*}{ 离 } & 99.1 \\
\hline & & \pm 1.5 & & \pm 1.2 & & \pm 1.5 & & \pm 1.2 & & \pm 1.1 & & \pm 1.7 \\
\hline ТФ & & 86.4 & & 88.5 & & 93.4 & & 95.8 & & 98.1 & & 99.3 \\
\hline $1 \Psi$ & & \pm 1.3 & & \pm 1.6 & & \pm 1.4 & & \pm 1.4 & & \pm 1.3 & & \pm 1.8 \\
\hline КфК & & 84.9 & & 87.5 & & 92.8 & & 95.1 & & 97.3 & & 99.5 \\
\hline & & \pm 1.2 & & \pm 1.2 & & \pm 1.5 & & \pm 1.3 & & \pm 1.5 & & \pm 1.5 \\
\hline УМ & & 84.7 & & 88.1 & & 93.8 & & 95.9 & & 97.2 & & 99.8 \\
\hline & & \pm 1.7 & & \pm 1.1 & & \pm 1.4 & & \pm 1.7 & & \pm 1.6 & & \pm 1.9 \\
\hline \multirow{2}{*}{ ХгК } & & 86.8 & & 88.9 & & 94.1 & & 96.1 & & 98.4 & & 99.7 \\
\hline & & \pm 1.8 & & \pm 1.3 & & \pm 1.3 & & \pm 1.4 & & \pm 1.8 & & \pm 1.4 \\
\hline
\end{tabular}

АУ БАУ-А наиболее полно сорбирует все исследуемые БАВ при ламинарном перемешивании в течение 15-30 мин, а при турбулентном - за 3-6 мин и достигает 
практически 99\%. Для выяснения механизма сорбции БАВ построены изотермы сорбции и их линеаризация (рис. 2 и 3 ).

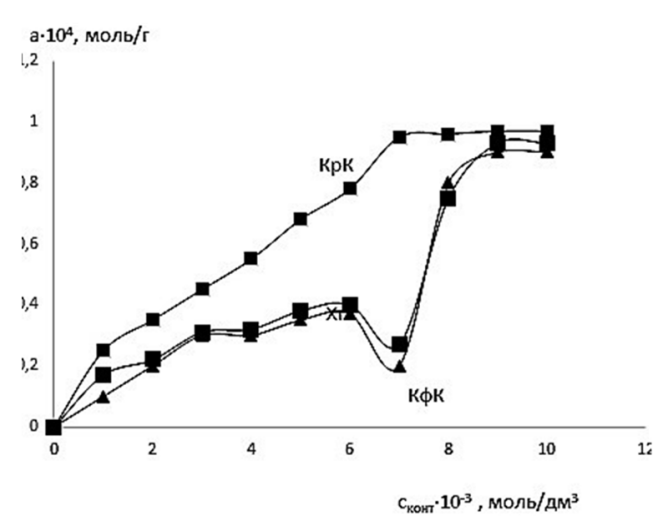

a

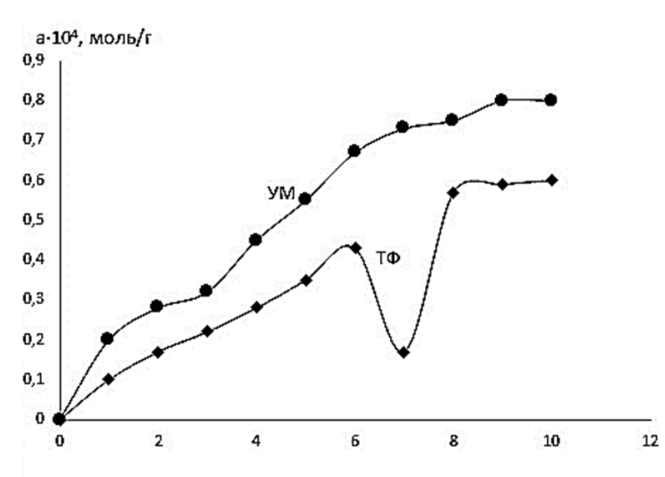

б

Рис. 2. Изотермы сорбции БАВ из стандартных образцов: а)водноэтанольных растворов КрК, КфК, ХгК; б) водно-этанольных растворов УМ, ТФ.

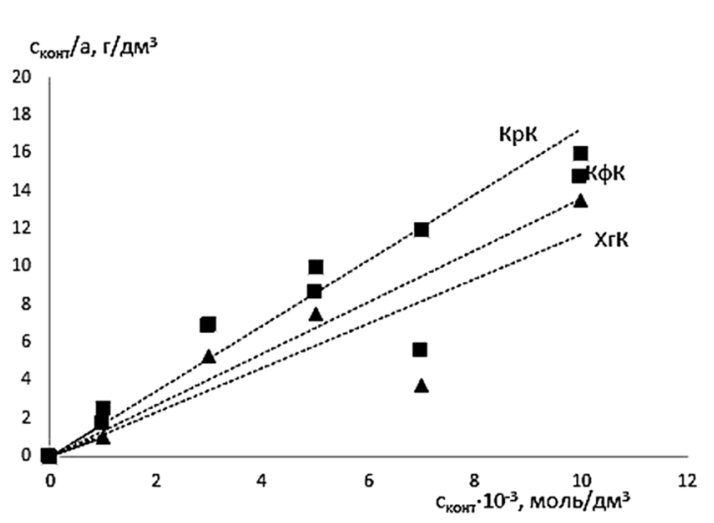

a

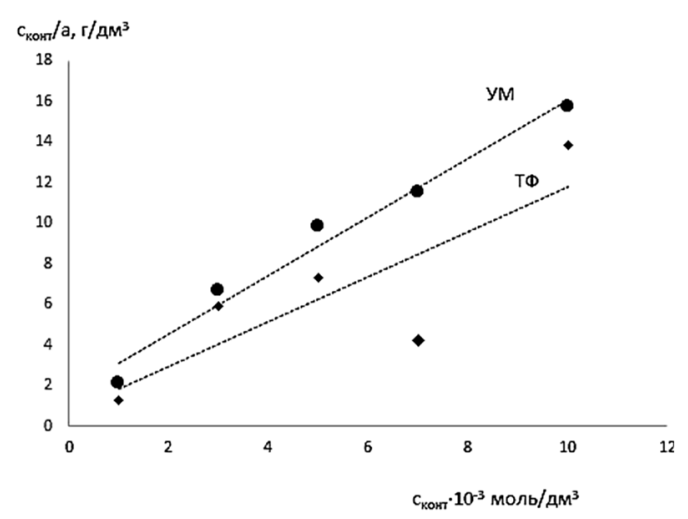

б

Рис. 3. Линеаризация изотерм сорбции БАВ из стандартных образцов а)водно-этанольных растворов КрК, КфК, ХгК; б) водно-этанольных растворов УМ, ТФ.

Вид изотерм сорбция исследуемых БАВ на БАУ-А подтверждает, что сорбция всех соединений протекает по механизму физической сорбции. При этом, изотермы адсорбции УМ и КрК имеют вид изотермы Ленгмюра, что свидетельствует о монослойной адсорбции, изотермы КфК, ХгК и ТФ относятся к изотермам II типа (изотерма Генри) по классификации БДДТ, что соответствует полимолекулярной адсорбции и описывается уравнением БЭТ. Это вероятно связано с особенностями химического строения этих соединений. Так, в молекулах КфК, ХГК и ТФ содержатся дополнительные гидрофильные ОН-группы, способные образовывать как межмолекулярные, так и внутримолекулярные водородные связи.

В табл. 3 приведены рассчитанные физико-химические параметры с использованием теории молекулярной адсорбции (уравнения Фрейндлиха и Ленгмюра), полимолекулярной адсорбции (модель БЭТ) и теории объемного заполнения микропор (уравнение Дубинина-Радушкевича) [23].

БАВ в статических условиях практически не десорбируются $(\mathrm{R} \leq 1 \%)$, поэтому десорбцию БАВ из активного угля БАУ-А осуществляли в динамических условиях (рис.4). 
Таблица 3. Параметры адсорбции БАВ АУ БАУ-А рассчитанные по уравнениям Ленгмюра, Фрейндлиха, Дубинина-Радушкевича и БЭТ.

\begin{tabular}{|c|c|c|c|c|c|}
\hline \multirow{2}{*}{$\begin{array}{c}\text { Параметры сорб- } \\
\text { ции }\end{array}$} & \multicolumn{5}{|c|}{ БАВ } \\
\hline & КрК & ТФ & КфК & УМ & ХГК \\
\hline \multicolumn{6}{|c|}{ по уравнению Ленгмюра } \\
\hline$-\Delta \mathrm{Go}$, кДж/моль & 32.56 & 28.45 & 25.56 & 30.45 & 29.45 \\
\hline$\alpha \infty$, ммоль/Г & 0.00027 & 0.00023 & 0.00021 & 0.00025 & 0.00022 \\
\hline \multicolumn{6}{|c|}{ по уравнению Фрейндлиха } \\
\hline $1 / \mathrm{n}$ & 8.11 & 7.6 & 7.5 & 7.9 & 7.7 \\
\hline $\mathrm{b}$ & $5.72 \cdot 10^{-4}$ & $7.3 \cdot 10^{-11}$ & $6.9 \cdot 10^{-11}$ & $5.07 \cdot 10^{-4}$ & $7.8 \cdot 10^{-11}$ \\
\hline \multicolumn{6}{|c|}{ по уравнению Дубинина-Радушкевича } \\
\hline$\alpha_{0}, \Gamma / \Gamma$ & 0.076 & 0.030 & 0.029 & 0.064 & 0.32 \\
\hline $\mathrm{E}^{\mathrm{o}}$, кДж/моль & 14.76 & 7.8 & 7.6 & 14.13 & 8.1 \\
\hline \multicolumn{6}{|c|}{ по уравнению БЭТ } \\
\hline Q, кДж/моль & 9.68 & 4.61 & 4.32 & 9.34 & 5.1 \\
\hline - & 0.185 & 0.054 & 0.051 & 0.143 & 0.063 \\
\hline
\end{tabular}

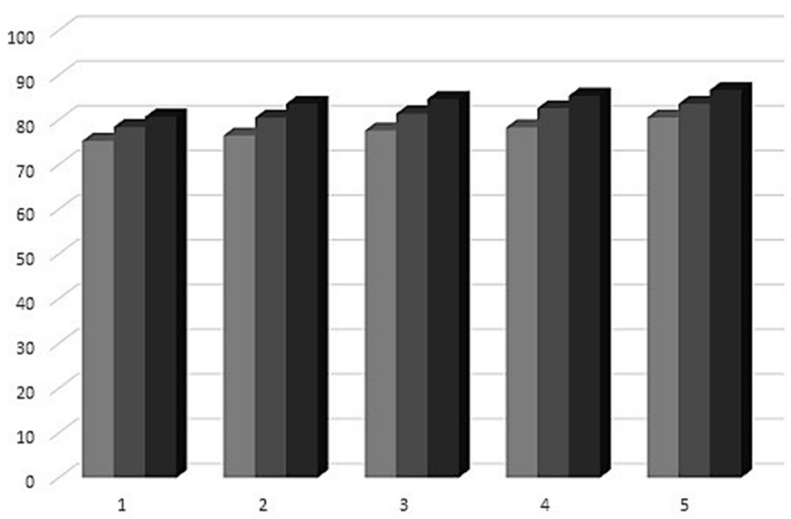

Рис. 4. Диаграмма зависимости выхода (\%) БАВ (1 - КрК; 2 - ТФ, 3 - КфК, 4 - УМ; 5 - ХгК) от состава элюирующего раствора: вода - этанол (первый столбец); вода - ацетонитрил (второй столбец); метанол (третий столбец).

Полученные диаграммы показывают, что при использовании в качестве элюента бинарной смеси вода - этанол, вода - ацетонитрил или метанол выход БАВ составляет 73-83\%, элюирование БАВ составляет 30 мин.

\section{Заключение}

Таким образом, показано что активный уголь БАУ-А обладает высокой адсорбционной способностью по отношению к мономерным полифункциональным природным БАВ растительного происхождения (коричной и гидроксикоричных кислот), таксифолина и умбеллиферона. Применение в качестве элюирующих растворов вода этанол, вода - ацетонитрил или метанол позволяет выделить из сорбента до 83 \% БАВ. Полученные экспериментальные данные позволяют рекомендовать марку АУ БАУ-А в качестве эффективного сорбента для извлечения БАВ из водных или водно-этанольных растворов растительных объектов для последующего их выделения.

\section{Список литературы}

1. Яшин Я.И., Веденин А.Н., Яшин А.Я. // Сорбиионные и хроматографические проuесcы. 2017. T.17. №3. С. 496-505.
2. Ложкин А.В., Саканян Е.И. // Химикофармацевтический журнал.2006. Т. 40. № 6. C. 47-56. 
3. Lallemand L.A., Zubieta C., Lee S.G., Wang Y. et al. // Plant Physiology. 2012. Vol. 160. pp. 249-260.

4. Upadhyay R., Rao L.J.M. // Critical Reviews in Food Science and Nutrition. 2013. Vol. 53. pp. 968-984.

5. Trandafir I., Nour V., Ionica M. // Arch Latinoam Nutr. 2013. Vol. 63. No 1. pp. 87-94.

6. Mithilesh S, Alok JAK, Navam H, Ashiwini KR. et al. // J. Food Sci. Technol. 2014. Vol. 51. Pp. 2070-2077.

7. Рогожин В.В., Перетолчин Д.В., Рогожина Т.В. // Известия вузов. Прикладная химия и биохимия. 2012. №1(2). С. 68-74.

8. Государственная фармакопея. Российская Федерация. XIV издание. М. 2018. Т. 4. $1833 \mathrm{c}$.

9. Подолина Е.А., Ханина М.А., Рудаков О.Б., Небольсин А.Е. // Вестник ВГУ. Серия: Биология, Химия, Фармаџия. 2018. № 2. С. 2835.

10. Подолина Е.А., Ханина М.А., Рудаков О.Б., Небольсин А.Е. // Химия растительного сырья. 2019. № 3. С. 145-152

11. Подолина Е.А., Ханина М.А., Лежнина М.Г., Кузнецова Ю.А. // Вестник ВГУ. Серия: Биология, Химия, Фармация. 2019. № 4. С.3338

12. Темердашев 3.А., Милевская В.В., Киселева Н.В., Верникова Н.А. и др. // Аналитика и контроль. 2013. Т. 17. № 2. С. 211-218.

13. Asano M. // Molecules. 2014. Vol. 19. No 8. pp. 12486-12499.
14. Marino T., Galano A., Russo N. // J Phys Chem B. 2014. Vol. 118. No 35. pp. 1038010389.

15. Селеменев В.Ф., Ланцузская Е.В., Крисилов А.В., Орос Г.Ю. и др. // Вестник ВГУ. Серия: Биология, Химия, Фармачия. 2015. № 3. C. 31-36.

16. Валов Р.И., Ларионова И.С., Ханина М.Г., Родин А.П. // Фармация. 2010. № 6. С. 28-31.

17. Подолина Е.А., Ханина М.А., Мухин В.М., Рудаков О.Б. и др. // Сорбиионные и хроматографические проиессы. 2018. Т. 18. № 6. C. 905-913.

18. Аверьянова Е.В., Школьникова М.Н. // Вестник КрасГАУ. 2015. № 4. С.49-54.

19. Евдокимова Е.В., Панова Т.М., Юрьев Ю.Л. // Вестник технологического универсиmema. 2017. T.20. № 6. C.124-126.

20. Золотов Ю.А. // Ж. аналит. химии. 2014. T. 69. № 1. C. 3.

21. Rios A., Escarpa A., Simonet B. Miniaturization of analytical systems. Principles, designs and applications. New York. Wiley. 2009. 384 p.

22. Рудаков О.Б., Селеменев В.Ф., Рудакова Л.В. Подолина Е.А. // Сорбционные и хроматографические прочессы. 2018. Т. 18. №4. C. 916-933.

23. Когановский А.М., Клименко И.А., Левченко Т.М., Рода И.Г. Адсорбция органических веществ из раствора. Л. Химия.1990. $256 \mathrm{c}$.

\title{
Sorption of cinnamic and hydrocinnamic (coffee and chlorogenic) acids, taxifolin and umbelliferone on active carbon BAU-A
}

\author{
(C) 2020 Podolina E.A. ${ }^{1,2,3}$, Khanina M.A. ${ }^{2}$, Mukhin V.M.' Lezhnina M.G. ${ }^{2}$, \\ Kuznetsova Yu.A. ${ }^{2}$, Nebolsin A.E. ${ }^{4}$ \\ ${ }^{1}$ FGOU VO Moscow Polytechnic University (branch in Elektrostal), Elektrostal \\ ${ }^{2}$ OGOU VO State Humanitarian-Technological University, Orekhovo-Zuevo \\ ${ }^{3}$ AO ENPO "Neorganika", Elektrostal \\ ${ }^{4}$ OAO "Partner", Voronezh
}

Monomeric polyfunctional natural biologically active substances (BAS) of plant origin include cinnamic and hydroxycoric (coffee, chlorogenic) acids, coumarins (umbelliferon) and Taxifolin, which are contained in small quantities in almost all medicinal plants (LRS). The aim of this study is to analyze the adsorption and desorption ability of NPC on active carbon BAU-A.

BAS were adsorbed from solutions of standard samples on BAU-A activated carbon with particle size 2.8-2.0 mm. BAS adsorption was carried out under stationary conditions with laminar mixing (using a Shaker 3.02 mixer) and with turbulent mixing (Vortex type mixer). The time of reaching the sorption equilibrium of BAS and their degree of sorption were experimentally determined. So with laminar mixing, the most complete 
sorption occurs within 15-30 minutes, and with turbulent mixing - within 3-6 minutes. The obtained isotherms of sorption of NPC on BAU-A belong to the L type (cinnamic acid and umbelliferone) and the S type (KfK, ChgK, TF) according to the Gibbs classification and confirm the physical mechanism of sorption.

Physicochemical parameters were calculated from adsorption isotherms using the theory of monomolecular adsorption (Freidlinch, Langmuir equations), polymolecular adsorption (BET model) and micropore volumetric theory (Dubinin-Radushkevich equation). The obtained Gibbs energy values confirm that natural phenolic compounds are adsorbed in micropores due to van der Waals forces, and the surface functional groups of AC form hydrogen sorbate-sorbent bonds. The BAS were desorbed under dynamic conditions on a column $180 \mathrm{~mm}$ long, $15 \mathrm{~mm}$ in diameter, AC layer height $20 \mathrm{~mm}$. As the eluting solutions, there were used polar individual (methanol) and binary (water - ethanol $\left(\varphi_{2}=0.5\right)$, water - acetonitrile $\left(\varphi_{2}=0.8\right)$ solvents. All eluting solvents elute with BAS by $73-83 \%$ within 30 min.

Thus, it was found that AC BAU-A is an effective adsorbent in relation to cinnamic and hydrocinnamic acids, umbelliferone and taxifolin. Methanol or binary mixtures (water - ethanol or water - acetonitrile) can be used to elute BAS; in this case, almost $83 \%$ of BAS can be extracted from the BAU-A sorbent. The active carbon BAU-A (GOST 6217-74 AO ENPO "Neorganika", Elektrostal, Moscow Region) is recommended for the extraction of cinnamic and hydrocinnamic acids, umbelliferone and taxifolin from aqueous solutions.

Keywords: activated carbon, adsorption, desorption, cinnamic and hydrocinnamic (coffee and chlorogenic) acids, taxifolin, umbelliferone.

\section{References}

1. Yashin Ya.I., Vedenin A.N., Yashin A.Ya., Sorbtsionnye i khromatograficheskie protsessy, 2017, Vol. 17, No 3, pp. 496-505.

2. Lozhkin A.V., Sakanyan E.I., Chemical and pharmaceutical journal, 2006, Vol. 40, No 6, pp. 47-56.

3. Lallemand L.A., Zubieta C., Lee S.G., Wang Y., Acajjaoui S. et al., Plant Physiology, 2012, Vol. 160, pp. 249-260.

4. Upadhyay R., Rao L.J.M., Critical Reviews in Food Science and Nutrition, 2013, Vol. 53, pp. 968-984.

5. Trandafir I., Nour V., Ionica M., Arch Latinoam Nutr., 2013, Vol. 63, No 1, pp. 87-94.

6. Mithilesh S, Alok JAK, Navam H, Ashiwini KR. Et al., J. Food Sci. Technol., 2014, Vol. 51, pp. 2070-2077.

7. Rogozhin V.V., Peretolchin D.V., Rogozhina T.V., Izvestiya vuzov. Applied chemistry and biochemistry, 2012, No 1(2), pp. 68-74.

8. State Pharmacopoeia. Russian Federation, XIV edition, M., 2018, Vol. 4, 1833 p.

9. Podolina E.A., Khanina M.A., Rudakov O.B., Nebolsin A.E., Vestnik VSU. Series: Biology, Chemistry, Pharmacy, 2018, No 2, pp.28-35.

10. Podolina E.A., Khanina M.A., Rudakov O.B., Nebolsin A.E., Chemistry of plant raw materials, 2019, No 3, pp. 145-152.

11. Podolina E.A., Khanina M.A., Lezhnina M.G., Kuznetsov Y.A., Bulletin of VSU. Series: Biology, Chemistry, Pharmacy, 2019, No 4, pp. 33-38.

12. Temerdashev Z.A., Milevskaya V.V., Kiseleva N.V., Vernikova N.A. et al., Analytics and control, 2013, Vol. 17, No 2, pp. 211-218.
13. Asano M, Molecules, 2014, Vol. 19, No 8, pp. 12486-12499.

14. Marino T., Galano A., Russo N., J Phys Chem B, 2014, Vol. 118, No 35, pp. 1038010389.

15. Selemenev V.F., Lanzuzskaya E.V., Krisilov A.V., Oros G.Yu. et al., Vestnik VSU. Series: Biology, Chemistry, Pharmacy, 2015, No 3, pp. 31-36.

16. Valov R.I., Larionova I.S., Khanina M.G., Rodin A.P., Pharmacy, 2010, No 6, pp. 28-31.

17. Podolina E.A., Khanina M.A., Mukhin V.M., Rudakov O.B. et al., Sorbtsionnye i khromatograficheskie protsessy, 2018, Vol. 18, No 6, pp. 905-913.

18. Averyanova E.V., Shkolnikova M.N., Vestnik Krasgau, 2015, No 4. pp. 49-54.

19. Evdokimova E.V., Panova T.M., Yuriev Yu.L., Bulletin of the technological University, 2017, Vol. 20, No 6, pp. 124-126.

20. Zolotov Yu.A., J. Analyt. Chemistries, 2014, Vol. 69, No 1, p. 3.

21. Rios A., Escarpa A., Simonet B. Miniaturization of analytical systems. Principles, designs and applications. New York, Wiley, 2009, 384 p.

22. Rudakov O.B., Selemenev V.F., Rudakova L.V. Podolina E.A., Sorbtsionnye $i$ khromatograficheskie protsessy, 2018, Vol. 18, No 4, pp. 916-933.

23. Koganovsky A.M., Klimenko I.A., Levchenko T.M., Roda I.G., Adsorption of organic substances from solution. 1. Chemistry, 1990, $256 \mathrm{p}$. 
Подолина Елена Алексеевна - профессор кафедры безопасности и здоровья, д. хим. н., доцент, Московский политехнический университет (филиал в г. Электросталь), Электросталь, тел.:8(49657)4-40-42

Ханина Миниса Абдуллаевна - зав.кафедрой химии, д. фарм.н., профессор, Государственный гуманитарно-технологический университет, Орехово-Зуево

Мухин Виктор Михайлович - начальник лаборатории АУЭСиК, д. тех. наук, профессор, Научно-производственное объединение «Неорганика», Электросталь

Лежнина Марина Георгиевна - доцент кафедры химии, к. фарм.н. Государственный гуманитарно-технологический университет, Орехово-Зуево

Кузнецова Юлия Александровна - старший преподаватель биолого-химического факультета, Государственный гуманитарно-технологический университет, Орехово-Зуево

Небольсин Александр Егорович - ведущий конструктор, ОАО «Партнер», Воронеж
Podolina Elena A. - Professor of the Health and Security Chair, Doctor of Chemistry, associate professor, Moscow Polytechnic University (branch in Elektrostal), Eletktrostal, e-mail: podolina70@mail.ru

Khanina Minisa A. - professor and the Head of the Chemistry Chair, Doctor of the Pharmaceuticals Sciences, Humanity-Technological State University, Orekhovo-Zuyevo, e-mail: khanina06@mail.ru

Mukhin Viktor M. - Head of the Laboratory of active carbons, elastic sorbents and catalysts, D. Tech. Sci., Professor, Scientific Production Association "Neorganika", Eletktrostal

Lejnina Marina G. - associate Professor of the Department of chemistry, Candidate of pharmaceutical sciences, Orekhovo-Zuyevo. e-mail: xm86@mail.ru

Kuznetsova Yuliya A. - Senior Lecturer, Faculty of Biology and Chemistry, State University of Humanities and Technology, OrekhovoZuyevo; e-mail: hronoksia@mail.ru

Nebolsin Aleksandr E.- Lead Designer, 4JSC «Partner», Voronezh, e-mail:mks36@mail.ru 